Fetal Diagnosis and Therapy
Fetal Diagn Ther 2013;33:103-109

DOI: $10.1159 / 000345092$
Received: July 23, 2012

Accepted after revision: October 1, 2012

Published online: December 12, 2012

\title{
Cardiovascular Transition to Extrauterine Life in Growth-Restricted Neonates: Relationship with Prenatal Doppler Findings
}

\author{
Sifa Turan ${ }^{\mathrm{a}}$ Ozhan M. Turan ${ }^{\mathrm{a}} \quad$ Mubadda Salim $^{\mathrm{b}} \quad$ Christoph Berg $^{\mathrm{c}}$ \\ Ulrich Gembruch ${ }^{c}$ Christopher R. Harman ${ }^{a}$ Ahmet A. Baschat ${ }^{a}$ \\ Departments of a Obstetrics, Gynecology and Reproductive Sciences, and ${ }^{b}$ Pediatrics, University of Maryland \\ School of Medicine, Baltimore, Md., USA; ' Department of Obstetrics and Prenatal Medicine, Friedrich Wilhelm \\ University, Bonn, Germany
}

\section{Key Words}

Cardiovascular transition - Fetal growth restriction •

Doppler ultrasound

\begin{abstract}
Objective: Cardiovascular status in fetal growth restriction (FGR) can be classified by the severity of individual Doppler abnormalities (early and late) or by the rate of clinical progression. We tested the hypothesis that aspects of the fetal cardiovascular status in FGR affect neonatal cardiovascular findings. Study Design: FGR cases [abdominal circumference $<5$ th percentile and an elevated umbilical (MCA) artery (UA) pulsatility index] had UA, middle cerebral artery and ductus venosus (DV) Doppler. Positive UA end-diastolic velocity and/or a low MCA pulsatility index denoted early and absent/reversed UA end-diastolic velocity, whereas an increased DV pulsatility index for veins denoted late responses. The rate of progression was classified into mild, progressive and severe. After delivery, shunt dynamics and blood flow across the patent ductus arteriosus (PDA), foramen ovale and atriaventricular valves, myocardial contractility and pharmacologic pressor requirement were noted at neonatal echocardiography. These findings were related to prenatal Doppler parameters. Results: In 94 patients, only individual
\end{abstract}

\section{KARGER}

Fax +4161306 1234

E-Mail karger@karger.ch

www.karger.com
(C) 2012 S. Karger AG, Basel

$1015-3837 / 13 / 0332-0103 \$ 38.00 / 0$

Accessible online at:

www.karger.com/fdt
Doppler parameters related to neonatal echocardiographic findings. Absent/reversed UA DV significantly predicted PDA with right to left shunt $(p=0.016)$. The pressor need for cardiovascular instability was observed in neonates with abnormal prenatal DV Doppler and with lower birth weights delivered at earlier gestational age ( $p<0.0001$ for both). Pressor need was significantly related to neonatal death (Nagelkerke $R^{2}=0.35, p=0.002$ ). Conclusion: A markedly abnormal UA Doppler predisposes growth-restricted neonates to persistence of fetal circulation associated with right to left shunting. Abnormal venous Doppler is a risk factor for cardiovascular instability which in turn significantly contributes to neonatal mortality. Further clarification of the neonatal cardiovascular transition may be helpful in guiding early neonatal assessment and management.

Copyright $\odot 2012$ S. Karger AG, Basel

\section{Introduction}

Placenta-based fetal growth restriction (FGR) impacts many organ systems of the developing fetus [1]. Prenatally, fetal cardiovascular function is particularly important for the maintenance of vascular homeostasis, organ perfusion as well as adequate nutrient delivery and pla- 
cental exchange. Because of the greater degree of underlying placental vascular abnormality, early-onset FGR established before 34 weeks gestation is associated with cardiovascular responses that can progress from arterial to venous Doppler abnormalities as placental dysfunction escalates [2]. Based on the evaluation of Doppler abnormalities, the impacts of placental dysfunction on the fetal cardiovascular status can be classified by their severity or the rate of progression. Late Doppler abnormalities such as absence or reversal of umbilical artery end-diastolic velocity (UA AREDV) and abnormal ductus venosus (DV) flow velocity waveforms indicate advanced vascular responses [3]. Longitudinally, deterioration to abnormal venous Doppler within 4-6 weeks of diagnosis has been defined as early severe and progressive deterioration, while mild progression may take up to 9 weeks and does not progress beyond cerebral Doppler abnormalities [4].

Prenatally, late vascular manifestations are associated with an increased risk of fetal cardiovascular decompensation [5]. Progressive myocardial cellular damage and dysfunction has been proposed as a mechanism which increases the risk of stillbirth and permanent vascular reprogramming in this setting [6-8]. We have previously demonstrated that growth-restricted neonates with abnormal venous blood flow prenatally require pressor support to maintain adequate blood pressure [9]. Because this raises the possibility that the severity of prenatal and postnatal cardiovascular abnormalities in FGR are related, we sought to test the hypothesis that prenatal cardiovascular characteristics of placental dysfunction impact the cardiovascular transition of growth-restricted neonates.

\section{Material and Methods}

This is a secondary analysis of FGR patients previously studied in a multicenter collaboration [10]. The original study enrolled singletons with accurate gestational age dating complicated by FGR [abdominal circumference $<5$ th percentile and a UA pulsatility index (PI) elevation of $>2$ standard deviations (SD)]. To allow evaluation of the degree and rate of progression, we analyzed a subset of patients who had at least three Doppler examinations before delivery and echocardiography in the neonatal period.

\section{Fetal Doppler Studies}

All patients had standardized assessment of the UA, middle cerebral artery (MCA), DV and umbilical vein (UV) by prospectively predefined standards [10]. The PI for each vessel was converted to its $\mathrm{z}$-score to exclude the effect of gestational age. For the UA, an index elevation of 2 SD was considered abnormal and EDV was classified as present EDV or AREDV. Brain sparing was defined as a decline of 2 SD in the MCA PI [11]. For the DV, a PI for vein elevation of $3 \mathrm{SD}$ was considered as abnormal and velocity during atrial systole was characterized as forward or absent/reversed. Pulsations in the UV were noted.

Elevated UA PI and brain sparing were classified as early Doppler changes. Late Doppler changes were categorized as UA AREDV or abnormal venous Doppler [3]. The rate of cardiovascular deterioration was categorized as mild (UA PI $<3 \mathrm{SD}$ or brain sparing progressing over 4 weeks), progressive (abnormal venous Doppler within 6 weeks) and early severe (abnormal venous Doppler within 4 weeks), as previously described [4].

Surveillance and delivery timing were at the discretion of the attending obstetrician. Perinatal characteristics, delivery details, gestational age, birth weight, Apgar scores, and UA blood gases were ascertained. Per institutional protocol, neonatal echocardiography was performed within $48 \mathrm{~h}$ of birth at the discretion of the managing neonatologist. At each institution, neonatal echocardiography was performed by 2 certified examiners and interpreted by an attending pediatric cardiologist. The following echocardiographic findings were extracted from the report or from stored examination tapes for the first cardiac ultrasound after birth: (1) visually assessed cardiac contractility; (2) atrioventricular valve regurgitation, assessed by color Doppler, and the use of spectral Doppler to evaluate tricuspid valve regurgitation in order to estimate the right ventricular systolic pressure; (3) presence of patent foramen ovale (PFO) and direction of the shunting; (4) aortic and pulmonary valves evaluated by color and spectral Doppler; (5) presence and size of patent ductus arteriosus (PDA) and shunting direction, and (6) requirement of pressor use to maintain blood pressure.

Individual Doppler abnormalities, degree of fetal cardiovascular deterioration (early versus late) and rate of progression (mild versus progressive or early severe) were related to neonatal echocardiographic findings. The relationship between neonatal echocardiographic findings and the degree of fetal acidemia, gestational age and birth weight was also evaluated. Continuous variables were analyzed with the Mann-Whitney U test after evaluation for normal distribution by the Kolmogorov-Smirnov test. Categorical variables were analyzed with the $\chi^{2}$ or Fisher's exact test depending on cell size. SPSS 13.0 (SPSS, Chicago, Ill., USA) was used for these analyses.

\section{Results}

Ninety-four patients met the study criteria. In the study group, the mean maternal age was 28 years (range $18-45)$, patients were predominantly Caucasians, and delivery was mainly by cesarean section (table 1 ).

The median UA, MCA and DV PI z-scores were 4.9 (range 1.4-33.5), -2.2 (range -3.8 to 2.4 ) and 1.4 (range -1.9 to 31.8$)$, respectively. UA EDV was absent in 18 (19\%) and reversed in 27 (29\%) of the fetuses. DV reversed/absent velocity was observed in $11(12 \%)$ of the cases. Based on the last examination, half of the fetuses $(n=47)$ were categorized as having late cardiovascular responses. Based on their longitudinal pattern of progression, 23 (24.5\%), 34 (35.2\%) and 37 (39.4\%) of patients had mild, 
Table 1. Characteristics of the study population $(n=94)$

\begin{tabular}{|c|c|}
\hline Age, years & $28[18-45]$ \\
\hline \multicolumn{2}{|l|}{ Race } \\
\hline Caucasian & $58(63)$ \\
\hline African American & $36(37)$ \\
\hline Parity & $0[0-3]$ \\
\hline Gestational age at delivery, weeks & $30[24-38.3]$ \\
\hline \multicolumn{2}{|l|}{ Delivery indication } \\
\hline Maternal & $43(45)$ \\
\hline Fetal & $52(55)$ \\
\hline \multicolumn{2}{|l|}{ Mode of delivery } \\
\hline Cesarean section & $87(92)$ \\
\hline Vaginal delivery & $8(8)$ \\
\hline Birth weight, $g$ & $835[440-2,100]$ \\
\hline Birth weight percentile, $\%$ & $0.6[0-18.5]$ \\
\hline Cord $\mathrm{pH}^{\circ}$ & $7.23[6.91-7.48]$ \\
\hline Cord base excess & $-4.5[-22.7$ to 3.5$]$ \\
\hline Early cardiovascular changes & $47(50)$ \\
\hline Late cardiovascular changes & $47(50)$ \\
\hline Mild placental dysfunction & $23(25)$ \\
\hline Progressive placental dysfunction & $34(36)$ \\
\hline Severe early-onset placental dysfunction & $37(39)$ \\
\hline \multicolumn{2}{|l|}{ Echocardiographic findings } \\
\hline Impaired contractility & $9(10)$ \\
\hline Pressor use & $23(24)$ \\
\hline PDA & $52(54)$ \\
\hline Right to left shunt & $5(5)$ \\
\hline Arterioventricular regurgitation & $22(23)$ \\
\hline PFO & $62(66)$ \\
\hline \multicolumn{2}{|l|}{ Neonatal complications } \\
\hline Respiratory distress syndrome & $74(79)$ \\
\hline Necrotizing enterocolitis & $12(13)$ \\
\hline Intraventricular hemorrhage & $25(27)$ \\
\hline Intraventricular hemorrhage grade III-IV & $10(11)$ \\
\hline Perinatal death & $8(9)$ \\
\hline
\end{tabular}

Data are presented as numbers with percentages in parentheses, or as medians with ranges in brackets.

progressive and severe placental dysfunction, respectively. PFO and PDA were the predominant echocardiographic findings, and almost one quarter of neonates required pressor support (table 1).

Neonates with UA AREDV prior to delivery were more likely to have right to left shunting in the PDA (5/23; $\mathrm{p}=0.016$ ). The rate of PDA right to left shunting increased from $11 \%$ when UA was absent to $29 \%$ for reversed EDV $(\mathrm{p}=0.012)$. While the proportional distribution for most neonatal echocardiographic findings was almost identical, late fetal cardiovascular responses were associated with a trend towards a higher rate of right to left shunting (Fisher's exact test, $\mathrm{p}=0.056$; table 2). Finally, the rate of progression was related to neonatal echocardiographic findings. Fetuses with progressive and severe placental insufficiency were delivered earlier than those with mild disease (table 3). There were no statistically significant differences in the distribution of neonatal echocardiographic findings in relation to the prenatal deterioration pattern. However, even neonates with mild placental dysfunction showed visual evidence of impaired contractility, required pressor support and had evidence of atrioventricular regurgitation.

Birth weight percentiles were not related to neonatal echocardiographic findings. Neonates requiring pressor support were delivered significantly earlier $(\mathrm{p}<0.0001$; fig. 1) and those that had a persistent foramen ovale had lower cord artery $\mathrm{pH}$ values ( $\mathrm{p}=0.02$; fig. 2 ).

Eight infants (8.5\%) died at a median of 7.5 days (range 3-120 days) after delivery. Compared to survivors, these infants had higher DV PI for vein Z-scores prenatally (3.72 vs. $1.2 ; \mathrm{p}=0.027)$, were delivered significantly earlier $(26.6 \pm 2.58$ vs. $30.1 \pm 3.25$ weeks; $p=0.003)$ and were more likely to require pressor support $(87.5 \%$; $\mathrm{p}<0.0001)$. Neonatal echocardiographic findings did not predict postpartum death. Regression analysis showed that the need for pressor support was the only significant predictor for postpartum death ( -0.827 to $3.42 \mathrm{x}$ need for pressor; Nagelkerke $\left.\mathrm{R}^{2}=0.35, \mathrm{p}=0.002\right)$.

\section{Discussion}

Progression of arterial and venous Doppler abnormalities in FGR is associated with prenatal evidence of myocardial dysfunction [7]. The observation that these fetuses are more likely to require pharmacologic blood pressure support after delivery raises the question if prenatal cardiovascular compromise has more widespread impacts on neonatal cardiac function [10]. In order to evaluate this possibility, we studied pregnancies complicated by FGR in whom prenatally available Doppler information allowed us to assess abnormalities in the placental, cerebral and venous circulations, grade the severity of placental dysfunction into early and late responses and characterize the rates of progression into mild, progressive and severe. This allowed us to relate neonatal echocardiographic findings to multiple aspects of the prenatal cardiovascular condition.

Our study population showed a balanced prevalence of early and late Doppler changes as well as of the three rates of progression. More severe Doppler abnormality and rapid rates of deterioration were associated with a greater degree of prematurity and acid-base disturbance 
Table 2. Perinatal and echocardiographic characteristics stratified by the severity of prenatal Doppler abnormalities

\begin{tabular}{lcc}
\hline & Early $(\mathrm{n}=47)$ & Late $(\mathrm{n}=47)$ \\
\hline Gestational age at delivery $^{1}$, weeks & $30.6[25.1-38.3]$ & $28.6[24-37.5]$ \\
Delivery indications $^{2}$ & & \\
$\quad$ Maternal & $26(55)$ & $15(32)$ \\
$\quad$ Fetal & $21(45)$ & $32(68)$ \\
Cesarean section for delivery & $42(89)$ & $44(94)$ \\
Birth weight ${ }^{1}, g$ & $1,015[460-2,000]$ & $690[440-2,100]$ \\
Birth weight percentile, $\%$ & $0.82[0-18.5]$ & $0.49[0-10.5]$ \\
Cord artery pH & $7.24[6.91-7.48]$ & $7.20[7.0-7.41]$ \\
Cord artery base excess & $-4.3[-18$ to 3.5] & $-4.9[-22.7$ to 2.6] \\
Echocardiographic findings & & $5(11)$ \\
$\quad$ Impaired contractility & $4(9)$ & $15(32)$ \\
Pressor use & $8(17)$ & $26(55)$ \\
PDA & $26(55)$ & $5(19)$ \\
Right to left shunt & 0 & $11(23)$ \\
Arterioventricular regurgitation & $11(23)$ & $31(66)$ \\
PFO & $31(66)$ & \\
\hline
\end{tabular}

Data are presented as numbers with percentages in parentheses, or as medians with ranges in brackets.

${ }^{1} \mathrm{p}<0.001$ (Mann-Whitney U test).

${ }^{2} \mathrm{p}=0.04$ ( $\chi^{2}$ test $)$

Table 3. Perinatal and echocardiographic characteristics stratified by the rate of progression of the placental disease

\begin{tabular}{|c|c|c|c|}
\hline & $\begin{array}{l}\text { Mild } \\
(n=23)\end{array}$ & $\begin{array}{l}\text { Progressive } \\
(\mathrm{n}=34)\end{array}$ & $\begin{array}{l}\text { Severe } \\
(\mathrm{n}=37)\end{array}$ \\
\hline Gestational week at delivery ${ }^{1}$ & $32[25.1-38.3]$ & $30[24.4-37.4]$ & $28.6[24-36.2]$ \\
\hline \multicolumn{4}{|l|}{ Delivery indications } \\
\hline Maternal & $11(48)$ & $10(29)$ & $10(27)$ \\
\hline Fetal & $12(52)$ & $24(71)$ & $27(73)$ \\
\hline Cesarean section for delivery & $19(83)$ & $30(88)$ & $37(100)$ \\
\hline Birth weight $1,2,3, \mathrm{~g}$ & $1,270[460-2,000]$ & $860[440-2,100]$ & $720[445-1,485]$ \\
\hline Birth weight percentile, $\%$ & $0.45[0-18.5]$ & $1.15[0-10.5]$ & $0.4[0-8.6]$ \\
\hline Cord $\mathrm{pH}$ & $7.23[7.08-7.48]$ & $7.24[6.91-7.41]$ & $7.21[7.0-7.41]$ \\
\hline Cord base excess & $-4.2[-13.5$ to 3.5$]$ & $-4.5[-18$ to 2.2$]$ & $-4.7[-22.7$ to 2.6$]$ \\
\hline \multicolumn{4}{|l|}{ Echocardiographic findings } \\
\hline Impaired contractility & $2(9)$ & $4(12)$ & $3(8)$ \\
\hline Pressor use & $5(22)$ & $7(21)$ & $11(30)$ \\
\hline PDA & $15(65)$ & $19(56)$ & $18(49)$ \\
\hline Right to left shunt & 0 & $3(9)$ & $2(5)$ \\
\hline Arterioventricular regurgitation & $6(26)$ & $6(18)$ & $10(27)$ \\
\hline $\mathrm{PFO}^{4}$ & $15(65)$ & $20(59)$ & $27(73)$ \\
\hline
\end{tabular}

Data are presented as numbers with percentages in parentheses, or as medians with ranges in brackets.

${ }^{1}$ Mild vs. progressive: $\mathrm{p}<0.05$.

${ }^{2}$ Mild vs. severe: $\mathrm{p}<0.001$.

${ }^{3}$ Progressive vs. severe: $\mathrm{p}<0.01$.

${ }^{4}$ Progressive vs. severe: $\mathrm{p}=0.049$ ( $\chi^{2}$ test). 
Fig. 1. This figure illustrates the distribution of delivery gestational age stratified by the absence $(\mathrm{A})$ or presence $(\mathrm{P})$ of neonatal cardiovascular abnormalities. PDA = Patent ductus arteriosus; $\mathrm{L}=$ left; $\mathrm{PFO}=$ patent foramen ovale.
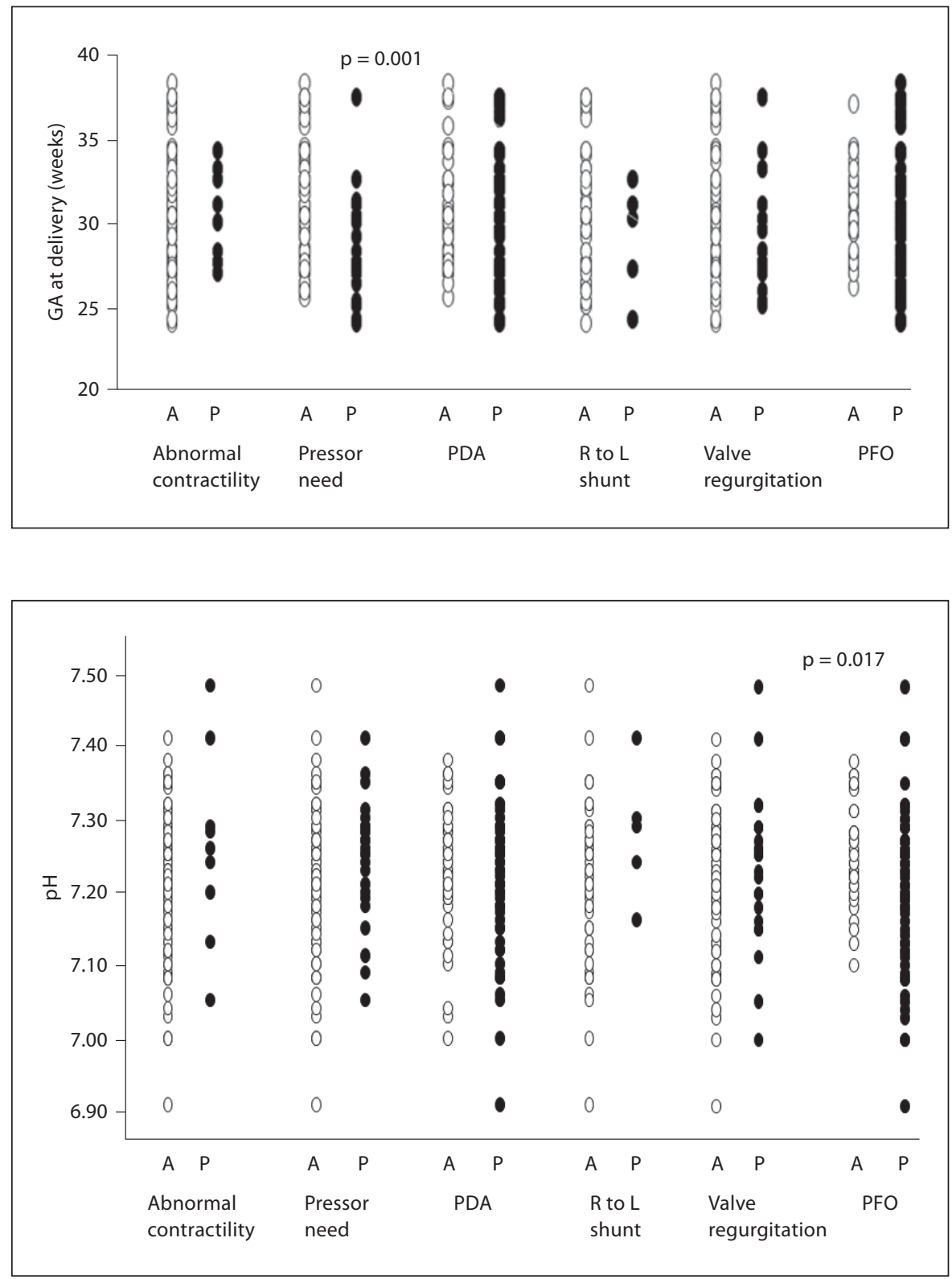

Fig. 2. This figure illustrates the distribution of birth $\mathrm{pH}$ stratified by absence (A) or presence $(\mathrm{P})$ of neonatal cardiovascular abnormalities. Abbreviations same as fig. 1. the face of prematurity and abnormal DV Doppler and appears to be an important risk factor for infant death.

Robel-Tillig and coworkers [12] matched forty growthrestricted neonates with abnormal prenatal Doppler studies and normal controls. They observed a higher frequency of PDA and diminished stroke volumes but a significantly higher heart rate resulting in an increased cardiac output. An increased heart rate and cardiac output is consistent with prenatal findings in FGR prior to the onset of cardiovascular decompensation [13]. Our observed frequency of PDA is consistent with this study as 
well as with more recent observations in preterm FGR [14]. Some investigators have suggested histologic changes in the ductus arteriosus as an explanation for its delayed closure in growth-restricted neonates [15]. However, appropriate closure of this vessel with standard medical therapy suggests that permanent structural damage and altered responsiveness may only affect a small proportion of these babies [16]. Persistence of increased intrapulmonary blood flow resistance as a consequence of chronic intrauterine hypoxemia effects on the pulmonary vasculature is an alternative mechanism that is supported by the predominance of right to left shunting in animal experiments and observations in humans [17-20]. Absent UA EDV could predispose to pulmonary vascular remodeling through its association with chronic intrauterine hypoxemia, increased right-sided afterload and increased pulmonary artery blood flow resistance [2123]. Relating fetal intrapulmonary Doppler studies to the persistence of the ductus arteriosus deserves further study to clarify this relationship.

While PFO is another neonatal echocardiographic finding that could result from increased right-sided pressures, it is only mentioned in case reports of growth-restricted infants [24]. Prenatally, Kiserud et al. [25] have shown that the size of the foramen ovale in FGR is more likely to be small. Therefore, it is unlikely that delayed closure in neonatal life is due to a larger size of the aperture. In contrast, increased right heart pressures could promote delayed closure of the foramen ovale in a similar fashion as proposed for the ductus arteriosus.

The degree and prevalence of cardiac dysfunction in FGR has been evaluated using venous Doppler as well as cardiac M-mode and Doppler techniques [6-8, 12, 14, 26, 27]. Because several mechanisms may lead to abnormal venous Doppler waveforms, their assessment only provides an indirect estimate of cardiac function $[1,7,9,28]$. Techniques for directly assessing cardiac function vary in sensitivity, and accordingly, demonstrate dysfunction at various stages of fetal compromise. Of these, tissue Doppler imaging and the myocardial performance index possess greater sensitivity, and therefore, may be abnordysfunction in a smaller proportion of fetuses $[6,14,28]$. In our study, significant cardiovascular instability was only seen in the small group of neonates requiring earlier delivery for persistently abnormal DV Doppler. Although we did not perform fetal cardiac function studies, our ob-

servation suggests that the later stages of prenatal cardiac dysfunction have a greater impact on neonatal circulatory transition and that cardiovascular instability may be responsible for over $30 \%$ of neonatal mortality. Since neonatal cardiovascular instability may result from myocardial dysfunction, the effects of persistent fetal circulation, impacts of mechanical ventilation clarification of these relationships may become important in modifying early neonatal management [31-33].

The disadvantage of our study is due to its retrospective nature and the secondary analysis. As a consequence, direct correlation of cardiac function parameters obtained immediately prenatally and postnatally is lacking. Therefore, we cannot provide the parameters that could distinguish between normal and abnormal cardiovascular transition. The echocardiographic findings are largely based on subjective assessments that are likely to only detect major findings with limited reproducibility when compared to more sophisticated quantitative methods. The strength lies in the prospectively standardized prenatal assessment of the fetal condition and the availability of cross-sectional and longitudinal Doppler information in a relatively large group of high-risk FGR pregnancies enabling us to relate several aspects of the fetal condition to neonatal echocardiographic findings.

In summary, our study indicates that markedly abnormal UA Doppler predisposes growth-restricted neonates to persistence of the fetal circulation in association with right to left shunting. A smaller group with abnormal venous Doppler is at risk of cardiovascular instability which is a significant contributor to neonatal mortality. The clarification of the vascular mechanisms that contribute to this risk may be of importance to guide early neonatal cardiac assessment and management, and accordingly, deserves further study. mal in almost $60 \%$ of growth-restricted fetuses before venous Doppler deterioration [29, 30]. In the later stages of compromise when venous Doppler becomes persistently abnormal, cardiac output falls due to significant cardiac

References $\checkmark 1$ Baschat AA: Fetal responses to placental insufficiency: an update. BJOG 2004;111:10311041.

2 Hecher K, Bilardo CM, Stigter RH, Ville Y, Hackelöer BJ, Kok HJ, Senat MV, Visser GH: Monitoring of fetuses with intrauterine growth restriction: a longitudinal study. Ultrasound Obstet Gynecol 2001;18:564-570.

- 3 Ferrazi E, Bozzo M, Rigano S, Bellotti M, Morabito A, Pardi G, Battaglia FC, Galan HL: Temporal sequence of abnormal Doppler changes in peripheral and central circulatory systems of the severely growth restricted fetuses. Ultrasound Obstet Gynecol 2002; 19:140-146.
Turan/Turan/Salim/Berg/Gembruch/ Harman/Baschat 
-4 Turan OM, Turan S, Gungor S, Berg C, Moyano D, Gebruch U, Nicolaides KH, Harman C, Baschat AA: Progression of Doppler abnormalities in intrauterine growth restriction. Ultrasound Obstet Gynecol 2008;32: 160-167.

5 Bilardo CM, Wolf H, Stigter RH, Ville Y, Baez E, Visser GH, Hecher K: Relationship between monitoring parameters and perinatal outcome in severe, early intrauterine growth restriction. Ultrasound Obstet Gynecol 2004;23:119-125.

6 Rizzo G, Capponi A, Rinaldo D, Arduini D, Romanini C: Ventricular ejection force in growth-retarded fetuses. Ultrasound Obstet Gynecol 1995;5:247-255.

-7 Crispi F, Hernandez-Andrade E, Pelsers MM, Plasencia W, Benavides-Serralde JA, Eixarch E, Le Noble F, Ahmed A, Glatz JF, Nicolaides KH, Gratacos E: Cardiac dysfunction and cell damage across clinical stages of severity in growth-restricted fetuses. Am J Obstet Gynecol 2008;199:254.

8 Baschat AA, Harman CR: Venous Doppler in the assessment of fetal cardiovascular status. Curr Opin Obstet Gynecol 2006;18:156-163.

-9 Baschat AA, Gembruch U, Reiss I, Gortner L, Weiner CP, Harman CR: Relationship between arterial and venous Doppler and perinatal outcome in fetal growth restriction. Ultrasound Obstet Gynecol 2000;16:407413.

10 Baschat AA, Cosmi E, Bilardo CM, Wolf H, Berg C, Rigano S, Germer U, Moyano D, Turan S, Hartung J, Bhide A, Muller T, Bower S, Nicolaides KH, Thilaganathan B, Gembruch U, Ferrazzi E, Hecher K, Galan HL, Harman CR: Predictors of neonatal outcome in early-onset placental dysfunction. Obstet Gynecol 2007;109:253-261.

11 Wladimiroff JW, Tonge HM, Stewart PA: Doppler ultrasound assessment of cerebral blood flow in the human fetus. Br J Obstet Gynecol 1986;93:471-475.

12 Robel-Tillig E, Knupfer M, Vogtmann C: Cardiac adaptation in small for gestational age neonates after prenatal hemodynamic disturbances. Early Hum Dev 2003;72:123129.

13 Rizzo G, Arduini D: Fetal cardiac function in intrauterine growth retardation. $\mathrm{Am} \mathrm{J} \mathrm{Ob-}$ stet Gynecol 1991;165:876-882.
4 Rakza T, Magnenant E, Klosowski S, Tourneux P, Bachiri A, Storme L: Early hemodynamic consequences of patent ductus arteriosus in preterm infants with intrauterine growth restriction. J Pediatr 2007;151:624628.

15 Ibara S, Tokunaga M, Ikenoue T, Murata Y, Hirano T, Asano, H, Uemura Y: Histologic observation of the ductus arteriosus in premature infants with intrauterine growth retardation. J Perinatol 1994;14:411-416.

16 Yang CZ, Lee J: Factors affecting successful closure of hemodynamically significant patent ductus arteriosus with indomethacin in extremely low birth weight infants. World J Pediatr 2008;4:91-96.

17 Reid LM: Constrictive and restrictive pulmonary hypertension in the newborn and infant. Am J Cardiovasc Pathol 1987;1:287299.

18 Goyal R, Leitzke A, Goyal D, Gheorghe CP, Longo LD: Antenatal maternal hypoxic stress: adaptations in fetal lung renin-angiotensin system. Reprod Sci 2011;18:180-189.

19 Rueda-Clausen CF, Morton JS, Davidge ST: Effects of hypoxia-induced intrauterine growth restriction on cardiopulmonary structure and function during adulthood. Cardiovasc Res 2009;81:713-722.

20 Haworth SG, Reid L: Persistent fetal circulation: newly recognized structural features. J Pediatr 1976;88:614-620.

21 Rozance PJ, Seedorf GJ, Brown A, Roe GB, O’Meara MC, Gien J, Tang JR, Abman SH: Intrauterine growth restriction decreases pulmonary alveolar and vessel growth and causes pulmonary artery endothelial cell dysfunction in vitro in fetal sheep. Am J Physiol Lung Cell Mol Physiol 2011; 301:L860-L871.

22 Groenenberg IA, Baerts W, Hop WC, Wladimiroff JW: Relationship between fetal cardiac and extra-cardiac Doppler flow velocity waveforms and neonatal outcome in intrauterine growth retardation. Early Hum Dev 1991;26:185-192.

23 Mäkikallio K, Jouppila P, Räsänen J: Retrograde net blood flow in the aortic isthmus in relation to human fetal arterial and venous circulations. Ultrasound Obstet Gynecol 2002;19:147-152.

24 Filippi L, Palermo L, Pezzati M, Dani C, Matteini M, De Cristofaro MT, Rubaltelli FF: Paradoxical embolism in a preterm infant. Dev Med Child Neurol 2004;46:713-716.
25 Kiserud T, Chedid G, Rasmussen S: Foramen ovale changes in growth-restricted fetuses. Ultrasound Obstet Gynecol 2004;24:141146.

26 Veille J, Hanson R, Steele L, et al: M-mode echocardiographic evaluation of fetal and infant hearts: longitudinal follow-up study from intrauterine life to year one. Am J Obstet Gynecol 1996;175:922-928.

- 27 Kaukola T, Rasanen J, Herva R, Patel DD, Hallman M: Suboptimal neurodevelopment in very preterm infants is related to fetal cardiovascular compromise in placental insufficiency. Am J Obstet Gynecol 2005; 193:414420.

28 Bellotti M, Pennati G, De Gasperi C, Bozzo M, Battaglia FC, Ferrazzi E: Simultaneous measurements of umbilical venous, fetal hepatic, and ductus venosus blood flow in growth-restricted human fetuses. Am J Obstet Gynecol 2004;190:1347-1358.

29 Comas M, Crispi F, Cruz-Martinez R, Figueras F, Gratacos E: Tissue Doppler echocardiographic markers of cardiac dysfunction in small-for-gestational age fetuses. Am J Obstet Gynecol 2011;205:57.e1-e6.

30 Cruz-Martinez R, Figueras F, BenavidesSerralde A, Crispi F, Hernandez-Andrade E, Gratacos E: Sequence of changes in myocardial performance index in relation to aortic isthmus and ductus venosus Doppler in fetuses with early-onset intrauterine growth restriction. Ultrasound Obstet Gynecol 2011:38:179-184.

31 Guajardo C, Mandelbaum V, Linderkamp O: Cardiac output and cerebral blood flow velocity in small for gestational age infants during the first 5 days of life. Early Hum Dev 1994;37:187-193.

- 32 Takashi Y, Harada K, Ishida A, Tamura M, Tanaka T, Takada G: Changes in left ventricular volume and systolic function before and after the closure of ductus arteriosus in fullterm infants. Early Hum Dev 1996;44:77-85.

33 Yoshido Y, Barry G, Emmanouilides C: Ventricular systolic time intervals by simultaneous echocardiographic recording of the semilunar valves during the first days of life: a study of normal newborn infants. J Clin Ultrasound 1983;11:431-436. 